\title{
Da Morte, da Vida e dos Tempos de Morte e de Vida da Traduçãa ${ }^{1}$
}

\author{
Of Death, of Life and of Times of Death \\ and Life of the Translation
}

Mauricio Mendonça Cardozo

\section{RESUMO}

Se partimos do princípio de que um pensamento contemporâneo sobre a tradução não pode prescindir de uma integração consequente das noções complexas de subjetividade e de linguagem que se nos impõem na contemporaneidade, a partir das quais reconhecemos o tradutor em sua condição de sujeito, a tradução como atividade transformadora e de ordem crítica e seu produto, o texto traduzido, como um objeto singular, não podemos ignorar a ideia de que, para além de representar uma forma de vida $e$ de morte para a obra original, o texto traduzido constitui, ele mesmo, uma forma singular de vida e de morte. Diante disso, é preciso levar em consideração que, para além do que representa temporalmente para outros textos (como a obra original), o texto traduzido também instaura uma forma de temporalidade que é a sua: um tempo da tradução. E é preciso pensar, igualmente, nas consequências desse dimensionamento temporal da tradução para nossa relação de leitores e críticos com o texto traduzido. No âmbito deste trabalho, caberá discutir e problematizar, preliminarmente, alguns aspectos da questão do tempo da tradução, entendida, aqui, a partir da forma singular de vida e de morte que a tradução constitui.

Palavras-chave: tradução e tempo; tradução e vida; tradução e morte.

1 Uma versão preliminar deste texto foi apresentada no Simpósio Tradução, Contemporaneidade, Extemporaneidade, realizado no âmbito do XV Encontro da ABRALIC, em setembro de 2016.

* UFPR/CNPq 
Cardozo, M. M.

Da Morte, da

Vida e dos

Tempos de

Morte e de Vida

da Tradução
ABSTRACT

Starting from the point of view that a contemporary thought on translation cannot ignore a consequent integration of the contemporary notions of subjectivity and language - recognizing the translator as a subject, the translation practice as a transformative and critical activity, and its product, the translated text, as a singular object -, one cannot ignore the idea that, beyond representing a form of life and death to the original text, the translated text also constitutes in itself a singular form of life and death. Therefore, it is necessary to take into consideration that, notwithstanding the temporality that the translated text represents to other texts (such as the original), it also establishes a temporality of its own: a time of the translation. And as readers and critics, it is also necessary to consider the consequences of this time dimensioning of the translation in our relationship with the translated text. This essay aims at discussing preliminarily some aspects of the issue of time of the translation, understood here as the singular form of life and death constituted by the translation.

Keywords: translation and time; translation and life; translation and death.
Revista Letras,

Curitiba, UFPR, n. 95 46-59, jan./jun. 2017. ISSN 2236-0999 (versão eletrônica) 
A morte é uma flor que floresce uma só vez. Mas quando ela floresce, floresce sem igual. Floresce, não no tempo, floresce quando quer.

Paul Celan ${ }^{2}$

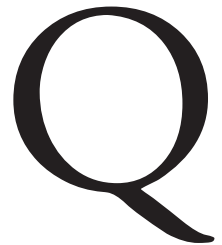
ue flor é essa flor da morte? Que morte é essa morte que floresce? Nesses versos de Paul Celan, a morte floresce no mesmo compasso em que esse florescer se mortifica. A flor (Blume) do primeiro hemistíquio ganha potência verbal na segunda parte do primeiro verso, e a força vital desse florescer (blühen) - de um florescer da flor da morte - é reiterada mais quatro vezes nos dois versos que se seguem, construindo-se assim uma tensão oximoresca que se nos impõe como uma morte-em-flor: uma morte como flor singular (que só floresce uma vez e sem igual, como só a ela é dado florescer), como flor voluntariosa (que floresce quando quer), como flor extemporânea (que não floresce num tempo determinado).

Se considerarmos que a flor é uma figura mais correntemente associada à quintessência da vida - de uma vida em flor ou em plena floração ${ }^{3}$ - e que a

2 CELAN, 2003, p.438-439, tradução minha.

3 Vide a primeira acepção que o DWB (Deutsches Wörterbuch von Jacob und Wilhelm Grimm) oferece para o verbo (blühen) em alemão: "den Gipfel des Wachstums erreichen" (alcançar o ponto mais alto do crescimento), cf. http://woerterbuchnetz.de/ DWB/?sigle=DWB\&mode=Vernetzung\&lemid=GB08691\#XGB08691. 
Cardozo, M. M.

Da Morte, da

Vida e dos

Tempos de

Morte e de Vida

da Tradução

poesia de Celan parece mais resistir do que ceder à convencionalidade das flores de retórica, teremos que enfrentar como mais do que mera figura de efeito essa morte que aflora na figura de uma flor. E se lembrarmos, ainda, que o verbo blühen (florescer), em alemão, aceita como sujeito trivial tanto a felicidade (Glück) quanto a infelicidade (Unglück) ${ }^{4}$, poderemos suspeitar que não é tão somente a vivacidade da flor que morre um pouco nessas construções oximorescas, e que tampouco é apenas a morte que se vivifica na força desse florilégio.

Nesses versos do poema $A$ morte (Der Tod), pulsam um fenecer e um florescer, que, ao invés de alimentarem a lógica de uma distensão binária, parecem antes se fundir e fundar a expressão de um viver a / à flor da morte. A um só tempo: sem crase, quando a flor da morte surge como objeto direto desse viver - a flor-da-morte é o que se vive; e com crase, quando à flor da morte surge como condição singular desse viver - à flor da morte é como se vive.

Composto em 1950 para figurar como peça da obra Papoula e Memória (Mohn und Gedächtnis ${ }^{5}$ ) - obra publicada em 1953 e que, já no título, traz a figura de uma flor -, o poeta excluiria esse poema de seu livro pouco antes de dá-lo à publicação. $\mathrm{Na}$ condição de uma espécie de flor de descarte - um malmequer? -, a publicação desses versos só ocorreria anos mais tarde, quando da edição da obra do espólio do autor. Como bem nos lembra Barbara Wiedemann ${ }^{6}$, o poema Der Tod é dedicado ao poeta e amigo Yvan Goll, cuja obra Celan traduziu e com quem Celan conviveu no período final e mais enfermo de sua vida (Goll morre em 1950). Após sua morte, a viúva, Claire Goll, proibiria a publicação das traduções preparadas por Celan, dando início a um processo legal em que acusava o poeta de plágio - infundado até onde se pôde comprovar e pessoalmente desgastante para Celan, esse episódio de litígio ficaria conhecido pela crítica como o Caso Goll.

Sem pretender avançar, aqui, as possibilidades de leitura que se abrem tanto para esses versos no contexto do restante do poema quanto para esse poema no contexto mais amplo da obra e da vida do poeta, essa breve passagem pela poesia de Paul Celan impele-nos a reconsiderar a ideia de morte apenas como final do curso da vida e, consequentemente, a ideia de vida apenas como o intervalo vital entre a concepção e a morte - uma visão mecanicista que o poema não apenas não parece pressupor, como parece colocar em questão. E talvez não possamos passar inteiramente à margem de um movimento semelhante de problematização dessas duas figuras quando, no campo das artes, em geral, e no da literatura, em particular, valemo-nos da noção de vida e de morte para pensarmos certos aspectos de nossos objetos.

Partindo disso, seria importante, por exemplo, questionarmos a que forma de pensamento sobre a literatura damos vida, hoje, ao pensarmos a obra literária e

Revista Letras,

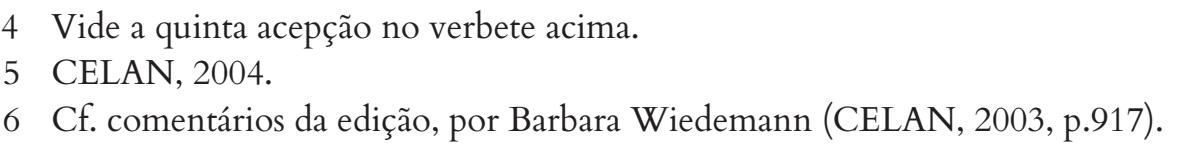

Curitiba, UFPR, n. 95 46-59, jan./jun. 2017. ISSN 2236-0999 (versão eletrônica) 
sua tradução a partir de uma noção de vida. Como se pode imaginar, as possíveis respostas a essa pergunta passam, necessariamente, pelo modo como entendemos a própria noção de vida - e não seria preciso lembrar, aqui, da infinidade de compreensões diferentes que se acumulam a esse respeito nas mais diversas áreas do saber.

E, nessa mesma perspectiva, seria igualmente importante perguntarmo-nos se há um sentido - ético, político ou ao menos heurístico - em continuarmos pensando hoje em dia a obra literária a partir de uma ideia de vida, especialmente se considerarmos válida a evidência de que a literatura, para além de seus círculos mais ou menos profissionais, parece ter uma participação cada vez mais discreta na vida dos indivíduos, distanciando-se cada vez mais daquilo que poderíamos identificar, genericamente, como a vida no mundo contemporâneo. Ou seja: qual o sentido de pensar a obra literária como forma de vida, se a literatura, hoje, mal cabe no tempo e no espaço desse âmbito que circunscrevemos como nossas vidas?

Também poderemos lembrar, é claro, que um dos sentidos de insistir em tal modo de pensar reside justamente em extrapolar a ordem dos cabimentos e em flagrar a condição naturalizada dessa ordem - a que sempre pudemos e ainda poderemos reagir - e que, portanto, não temos simplesmente de aceitar essa condição como dada, inequívoca e indiscutível, como ordem natural das coisas.

Tempo, morte, vida e tradução são questões notoriamente amplas e complexas, que circunscrevem um universo oceânico de discussão. Desses tantos mares - de dimensões pacíficas, de natureza atlântica - não se pretende aqui, senão, esboçar algumas inquietações.

No clássico ensaio A tarefa do tradutor (BENJAMIN, 2011), como bem irão destacar alguns de seus comentadores, Walter Benjamin, ao desenvolver as principais linhas de força de seu pensamento sobre a tradução, esboça também uma importante reflexão sobre a noção de vida da obra de arte. E para fazê-lo, empreende uma breve problematização da noção de vida, dando-lhe uma precisão de sentido que parece se impor como necessária aos interesses de sua reflexão.

É no bojo desse movimento que o pensador alemão irá afirmar, por exemplo, que a associação entre vida e obra não deve ser entendida como uma simples metáfora - recomendação que nos salta ainda mais aos olhos quando lembramos de quão intensa e organicamente o autor se vale das mais diversas metáforas para articular seu pensamento tradutório nesse ensaio. Ou seja, no caso da obra pensada a partir da figura da vida, não se trataria apenas de um como se, de falar metaforicamente da obra de arte enquanto forma de vida; ao 
Cardozo, M. M.

Da Morte, da Vida e dos

Tempos de

Morte e de Vida da Tradução

contrário, Benjamin insiste na ideia de que é mesmo de uma vida que se trata: objetivamente - como ele mesmo dirá (BENJAMIN, 2011, p.104).

Ao dar esse passo, o autor desloca a noção de vida de um dimensionamento meramente biológico e natural, inscrevendo-a numa dimensão histórica. Para Benjamin:

É somente quando se reconhece vida a tudo aquilo que possui história e que não constitui apenas um cenário para ela, que o conceito de vida encontra sua legitimação. Pois é a partir da história [...] que pode ser determinado, em última instância, o domínio da vida (p.105).

É importante notar aqui, como o faz Jeanne Marie Gagnebin na nota de número 44 à tradução de Susana Kampff Lages (BENJAMIN, 2011, p.106), que ao promover esse deslocamento da noção de vida de uma simples inscrição natural para sua inscrição na história, Benjamin também passa a fazer distinção entre uma forma de vida em sua mera expressão natural (das blosse Leben) e aquela que, para o pensador, mais parece importar a sua discussão: uma forma de vida que encontra finalidade para além de si mesma, num outro plano, no plano da história.

Tomando essa delimitação epistemológica como pano de fundo, Benjamin passa a operar, então, com as conhecidas distinções entre vida, sobrevida (ou sobrevivência) e pervivência da obra de arte. Para Benjamin, como sabemos, a tradução, nesse contexto, derivaria menos da vida (Leben) do que da sobrevida (Überleben) do original (BENJAMIN, 2011, p.104) - distinção que ganha ainda mais consistência à luz do redimensionamento da noção de vida mencionado anteriormente. Em outras palavras, a tradução derivaria menos da mera factualidade vital do original do que de sua capacidade de transcender historicamente os limites dessa factualidade, de-signando, assim, um estágio de sua pervivência (Fortleben).

O que eu gostaria de pontuar, nesse famoso movimento do pensamento benjaminiano, diz respeito precisamente às vidas que estão em jogo nesse modo de pensar a tradução.

Quando Benjamin discute a obra de arte, é obviamente da vida da obra de arte (ou da obra literária, em particular) que se trata, especialmente na expressão de sua sobrevivência e pervivência - afinal, como vimos, é esta a noção de vida que interessa ao pensador. No entanto, quando Benjamin passa a discutir a tradução da obra literária, é ainda da vida do original, é sempre da vida do original, é exclusivamente da vida do original que se trata. Embora o pensador eleve a traduzibilidade à condição de propriedade essencial da obra literária (BENJAMIN, 2011, p.103) e reserve à tradução o estatuto próprio de uma forma (BENJAMIN, 2011, p.102), é na obra original que Benjamin fará residir tanto essa propriedade quanto a sua lei. Nesse ensaio de Benjamin, a vida da tradução não tem lugar como tal - nem no sentido de uma factualidade vital própria, nem no sentido de uma transcendência própria dessa factualidade, em seu sentido

Revista Letras,

Curitiba, UFPr, n. 95 46-59, jan./jun. 2017. ISSN 2236-0999 (versão eletrônica) 
histórico; quando muito, dimensiona-se a tradução nos limites de um blosses Leben que nem mesmo é o seu, nos limites de uma mera manifestação vital do original' (BENJAMIN, 2011, p.104).

É nessa medida exata, aliás, que o autor dirá que as traduções não significam nada para o original; e que, ao contrário, elas é que deveriam a sua existência à condição de pervivência do original. Benjamin chega mesmo a ser categórico a esse respeito: "Nelas [nas traduções], a vida do original [é da vida do original que Benjamin fala aqui] alcança, de maneira constantemente renovada, seu mais tardio e mais abrangente desdobramento" (BENJAMIN, 2011, p.105). Em outras palavras: na reflexão de Benjamin, a tradução existe, cumpre sua função, constitui-se como uma forma, mas não é dimensionada nem nos termos de uma vida própria, nem como uma forma mais digna de vida $^{8}$, capaz de transcender a si mesma. À parte aqueles raros casos de exceção (Lutero, Voss, Hölderlin), que o autor se reserva o direito de entender a partir da mesma ótica das obras originais - sublinhe-se esse detalhe -, a tradução, nesse dimensionamento benjaminiano, torna-se uma espécie de morto vivo, implacavelmente entregue à ação vampiresca da obra original.

Se nisso podemos flagrar um aspecto do pensamento benjaminiano sobre a tradução que merece ser repensado mais atentamente do ponto de vista de um olhar contemporâneo, cabe observar, contudo, que não se trata, aqui, de demandar de Benjamin um dimensionamento conceitual da tradução que nos seja mais contemporâneo do que a ele. Embora tenha logrado avançar discussões que foram muito além do estado da reflexão tradutória em sua própria época, não se pode ignorar o fato de que estamos lidando com um pensamento que também não deixa de se inscrever, em alguma medida, no tempo de sua produção (1921). A coerência interna e a força desse pensamento - levando-se em conta sua repercussão, quiçá um dos ensaios mais importantes já escritos sobre a tradução da obra literária - não desobriga o crítico contemporâneo de enfrentar também as diferenças que se flagram nesse pensamento quando este é lido a partir do estado atual da pesquisa no campo da teoria e da filosofia da tradução.

Vale lembrar, ainda, que identificar a necessidade de refletir sobre a impressão trivial de que o texto traduzido alimenta os tempos de vida do original

$7 \mathrm{Ou}$, numa outra perspectiva, a tradução - termo que em português tem a felicidade acidental de indicar simultaneamente um processo e um produto - é minimizada em sua capacidade de produzir um objeto que tenha valor como tal (à diferença de outros), ficando reduzida à mera gestualidade de um traduzir, que teria sempre por objeto a obra dita original, amalgamada então numa temporalidade que é sempre, a um só tempo, a temporalidade de uma origem e de um por vir. Mesmo desse ponto de vista, teríamos de presumir aí uma projeção de continuidade do objeto, que, no entanto, também só tem lugar como um valor construído a partir da condição descontínua de toda prática humana, relacional, discursiva.

8 Caberia lembrar, ainda, que entre as tantas figurações metafóricas de que se vale Benjamin nesse ensaio, a mais vitalista - da casca e do fruto (Benjamin, 2011, p.111) - diz respeito a uma relação com a língua que é exclusivamente do domínio do original; essa mesma relação com a língua, no caso da tradução, é dimensionada por Benjamin por intermédio das figuras do manto real e do rei - se o rei é corpo e, portanto, vida, o manto, por mais que nobre, é instância inanimada. 
Cardozo, M. M.

Da Morte, da

Vida e dos

Tempos de

Morte e de Vida

da Tradução

- assim como o fazem também, a seu modo, outras formas de produção derivativa como, por exemplo, a crítica e o comentário - não implica necessariamente uma indiferença aos sentidos dessa impressão. Ao viajarmos de avião, às vezes temos a impressão de que nos locomovemos muito lentamente, e saber que estamos a uma velocidade imensa afeta muito pouco essa impressão. O que não podemos fazer é ignorar solenemente essa questão e continuar convivendo, atualmente, com a ideia de que uma preponderância (por mais que justificável) da relação original-tradução implique necessariamente o embargo (hoje injustificável) de todo e qualquer outro dimensionamento relacional, temporal e vital do texto traduzido.

A esta altura, cabe fazer um pequeno desvio por uma discussão abreviada disto que eu gostaria de chamar, aqui, de uma condição de infância da tradução.

Para certo modo de compreender a tradução - um modo que, a despeito de todos os esforços reflexivos das últimas décadas, infelizmente não podemos tributar apenas ao chamado senso comum -, não caberia ao texto traduzido outra coisa, senão, a tarefa de dizer de novo a obra original. E como, nos termos ideais em que se articula tal economia tradutória, nada mais se costuma aceitar para além ou aquém do dimensionamento unívoco dessa vocação, a única voz da tradução que se faz aceitável, nessa perspectiva, é a voz do original, a voz do outro em tradução. Em outras palavras: ao texto traduzido não se reservaria nem a possibilidade, nem o direito de ter uma voz própria. É a isso que chamo de uma condição de infância da tradução.

Entretanto, se formos minimamente consequentes com o dimensionamento mais complexo que as noções de sujeito e de linguagem alcançam na contemporaneidade, de que resulta o reconhecimento da tradução como atividade crítica e transformadora e do texto traduzido como um objeto singular - que, aliás, somente nessa condição de singularidade é capaz de cumprir sua destinação como tradução de outro texto -, seremos constrangidos a reconhecer uma ruptura do tradutor com essa condição de infância, em que o aprisionava certa visão idealizante e idealizada da tradução.

Assim, se por um lado podemos continuar operando com a ideia de que a tradução diz a obra original de novo, tal ruptura com a condição de infância nos leva a considerar, por outro lado, que não está dada, à tradução, a possibilidade de dizer o outro de novo sem dizer também, nesse mesmo gesto, alguma coisa sobre esse outro e sobre si mesma. A tradução também tem voz. A tradução diz muitas coisas. E é no modo particular com que vocaliza seus dizeres que se constitui sua singularidade.

Diante disso, é imperativo considerar que, para além de representar uma forma de vida para a obra original, o texto traduzido constitui, ele mesmo, em sua

Revista Letras,

Curitiba, UFPR, n. 95 46-59, jan./jun. 2017. ISSN 2236-0999 (versão eletrônica) 
e por sua singularidade, uma forma própria ${ }^{9} \mathrm{de} \operatorname{vida}^{10}$. E se não podemos ficar indiferentes a essa singularidade vital da tradução - que a projeta para além de uma mera expressão da vida de outrem -, tampouco podemos ignorar que isso implique sua inscrição na ordem do tempo, no plano da história.

\section{IV}

No primeiro capítulo de sua Prova do Estrangeiro (BERMAN, 2002), dedicado à discussão do papel fundador da tradução bíblica de Lutero na Alemanha, Antoine Berman, partindo da leitura de um excerto do ensaio Die Schrift und Luther, de Franz Rosenzweig (1969), coloca em destaque o que ele vai chamar de problema da historicidade geral da tradução. Como pressuposto, Berman assume a ideia de que a historicidade de uma obra (ele se refere às obras ditas originais) seria algo, senão evidente, ao menos indiscutível (BERMAN, 2002, p.56). Caberia, no entanto, pensar em que medida se pode falar também da historicidade de uma tradução.

Primeiramente, Berman pondera que não se pode confundir a historicidade de uma obra universalmente traduzida com a historicidade de suas traduções. Muitas das obras canônicas, plenamente históricas - como diz o autor -, não teriam sido contempladas necessariamente com nenhuma tradução de que se pudesse dizer que fez história. Para tanto, alguma dessas traduções teria de ter sido capaz de "se fazer notar por si mesma" (BERMAN, 2002, p.57). Volto mais 54 adiante a esse ponto.

Em seguida, operando a partir de uma circunscrição epistemológica que se mostra grandemente tributária da reflexão benjaminiana, Berman propõe o seguinte:

Convém chamar tradução histórica àquela que faz época enquanto tradução, aquela em que a tradução aparece como tal e tem acesso, assim, estranhamente, à posição de uma obra $\mathrm{e}$ não mais àquela de humilde mediação de um texto ele próprio histórico

(BERMAN, 2002, p.57, grifos meus)

Com base nisso, o autor promove então uma segunda distinção: entre uma historicidade mais geral da tradução - da tradução em sua destinação mais instrumental, de simples mediação -, condição na qual os textos traduzidos desempenhariam um papel de mera figuração na história de determinada obra; e uma historicidade especial ${ }^{11}$, que só se aplicaria em alguns casos mais raros, em

9 Vale lembrar que a condição dessa propriedade também não pode ser considerada nem óbvia nem inequívoca, desdobrando-se como outra questão importante da mesma discussão.

10 Cabe explicitar aqui o dimensionamento relacional dessa forma de vida, sempre na instância do outro, sempre como manifestação poiética na relação com um outro.

11 O termo não é proposto por Berman, proponho-o aqui apenas para efeito de síntese. 
Cardozo, M. M.

Da Morte, da Vida e dos

Tempos de

Morte e de Vida da Tradução
Revista Letras,

Curitiba, UFPr, n. 95 46-59, jan./jun. 2017. ISSN 2236-0999 (versão eletrônica) que certas traduções lograriam assumir um protagonismo e se tornariam, elas mesmas, plenas de história.

Ora, essa distinção representa também duas maneiras diferentes de se dimensionar a vida das traduções. E, a essa altura, cabe recuperar, aqui, a distinção que Benjamin faz entre uma vida restrita à esfera de seus próprios fins e uma vida capaz de se inscrever num outro plano, no plano da história: no caso daquelas traduções que não transcendem a condição de simples figurantes ${ }^{12}$ - porque ignoram essa possibilidade de transcendência, porque não se permitem, não querem ou não são capazes de fazê-lo -, teríamos uma vida tão indiferentemente dimensionada, que mal poderíamos chamá-la, de fato, de uma vida, a não ser pelo que essa manifestação discursiva representa da vitalidade de alguma outra instância - dimensionamento semelhante à condição de morto vivo a que me referi antes; já no caso das traduções que alcançam a condição de protagonistas, sua vida se dimensionaria, ao menos aproximativamente, nos mesmos termos que a vida de qualquer obra dita original.

Se o primeiro conjunto (o de figurantes) é constituído pela maioria absoluta das traduções literárias, os poucos exemplos que Berman faz figurar no segundo conjunto (o de protagonistas) são - de certo não por acaso - praticamente os mesmos exemplos que Benjamin menciona como casos de exceção: a bíblia de Lutero, o Homero de Voss, o Sófocles de Hölderlin, etc. (BENJAMIN, 2011).

Como já apontei anteriormente, o que faz com que uma tradução alcance essa condição especial de vida, segundo Berman, é sua capacidade de se fazer notar por si mesma (BERMAN, 2002, p.57), de chamar a atenção para sua condição de tradução. Ora, mas em cada um desses casos de exceção, seja por força das publicações que antecederam essas traduções (todas eram re-traduções), seja por força das circunstâncias estéticas, críticas, religiosas ou políticas em que se inscrevera sua produção e se inscreveria sua repercussão, havia sempre muito mais em jogo do que, simplesmente, a própria condição tradutória dessas obras. Ou seja, somadas suas contingências e suas circunstâncias, não há dúvidas de que essas traduções conseguiram catalisar, de modo extraordinário, uma forma muito particular de atenção. Mas se o fizeram, não o fizeram nem exclusivamente, nem predominantemente pela evidência de seu estatuto tradutório - via de regra, limitado e reduzido à tradicional condição de infância a que é relegada toda tradução. Ao contrário: se o fizeram, só o fizeram por força daquilo a que essas traduções se prestavam para além das obras que representavam; só o fizeram pelo que essas traduções representavam para além da opacidade de sua condição tradutória, pelo que tinham a dizer para além do que se esperava que dissessem como meras traduções. E se nisso se fizeram surpreendentes, só o fizeram porque - pela força da revolução político-religiosa (como no caso de Lutero) ou pelo impacto da monstruosidade crítico-estética (como no caso de Hölderlin) que passaram a representar - conquistaram um espaço de escuta, fazendo valer sua voz e provando-se, assim, uma forma digna de vida, capaz de se inscrever nos domínios da história.

12 Também esta formulação é minha, a partir de Berman. 
Nesse sentido, faz-se necessário repensar a justificativa que Berman encontra para a distinção $0^{13}$ entre uma historicidade geral e uma historicidade especial das traduções - que o autor localiza na capacidade de uma tradução chamar a atenção para sua condição tradutória. E podemos fazê-lo tomando por base um redimensionamento da noção de vida da tradução, nos termos do que se discutiu no item 3 deste trabalho a partir da leitura do famoso ensaio de Benjamin.

Assim, se assumimos que, para além do que representa para a obra dita original, a tradução também constitui uma forma singular de vida e que, em razão disso, a possibilidade de uma condição de infância da tradução não está dada, teremos de assumir, consequentemente, que toda tradução tem voz. A justificativa para a distinção das historicidades bermanianas, nesse sentido, não poderia residir simplesmente no reconhecimento de uma voz da tradução, uma vez que, por força de seu redimensionamento vital, teríamos então de assumir igualmente que toda e qualquer tradução tem a sua voz - nisso se diluiria sua força de traço distintivo.

A questão é que não basta ter voz; é preciso ter também o que dizer. Ou seja, uma vez que não está dada à tradução a possibilidade de não ter voz, o que se coloca em jogo, de fato, é o modo particular com que a tradução se vale de sua voz. E se podemos associar esse uso singular da voz tradutória ao imperativo crítico bermaniano do faire oeuvre ${ }^{14}$, poderemos dizer que traduzir, fazendo um uso singular - e crítico - de sua voz, será sempre também um modo de fazer vida.

No entanto, para distinguir-se (por vezes de modo tão extraordinário) nessa condição especial de historicidade, é preciso ainda que, para além de ter voz e de ter o que dizer, a tradução conquiste uma condição mínima de escuta, algo que - permitam-me reforçar aqui o óbvio - não depende somente da força crítica da tradução, nem apenas de sua capacidade de se fazer notar, mas também - e decisivamente - do modo como nos relacionamos com o texto traduzido enquanto leitores e críticos. Depende, portanto, do quanto nos interessa ler o texto traduzido para além do que ele representa do original - ou de uma certa compreensão do que seja o original; depende do quanto somos capazes de lê-lo em sua singularidade, de lê-lo como forma própria de vida, de lê-lo em seus tempos, como inscrição particular no plano da história.

Lembremos que as traduções exemplares mencionadas por Benjamin e Berman certamente lograram conquistar essa condição mínima de escuta. Mas também vale a pena lembrar que essa condição particular se constituiria apenas muito lentamente no caso das traduções monstruosas de Hölderlin - que somente no século 20, a partir da atenção especial que lhe dedicou o germanista Norbert von Hellingrath, seriam reconhecidas como um marco (BERMAN, 2002, p.282) - ou muito violentamente no caso da tradução revolucionária da

13 Cabe precisar aqui o movimento: trata-se de repensar apenas a justificativa para tal distinção. A distinção, em si, parece ser viável e criticamente produtiva.

14 “[...] le traducteur doit toujours vouloir faire oeuvre". (Berman, 1995, p. 92) 
Cardozo, M. M.

Da Morte, da

Vida e dos

Tempos de

Morte e de Vida

da Tradução

Bíblia de Lutero, que - para além do quanto passou a representar para a língua alemã - tornou-se o signo de uma revolução religiosa, ideológica política e econômica, a partir da qual se escreveram alguns dos capítulos mais sangrentos da história europeia - a exemplo da Guerra dos Trinta Anos - e se redesenharam os limites e contornos políticos de todo um continente.

Hoje, a monstruosidade - como sintoma - consistiria, antes, em perpetuar essa condição de indisponibilidade de escuta, que só faz minimizar o dimensionamento vital de qualquer tradução, reduzindo-a exclusivamente a uma forma de morte e mantendo-a prisioneira de uma condição infante, de uma condição de morto-vivo. Já a revolução - como horizonte -, passaria, hoje, por uma ética da escuta ${ }^{15}$, capaz de acolher a tradução no que ela tem a dizer para além do que diz ao cumprir sua destinação instrumental, capaz de acolher a tradução no que ela tem a dizer como uma forma de vida.

\section{V}

Mais acurado do que falar dos tempos do original e da tradução, seria então falar do original e da tradução como formas de tempo, como formas de morte e de vida.

Fazendo reverberar aqui a famosa fórmula de Koselleck (2006), poderíamos dizer que a escrita - tanto a da obra original quanto a do texto traduzido -, já a partir de sua cena de inscrição, habita a condição de uma forma passada de futuro (vergangene Zukunft). Pois, não the sendo possível coincidir temporalmente consigo mesma, ou melhor, não the sendo possível acontecer como uma forma de tempo que coincida com a forma de tempo que ela mesma instaura, a escrita seria, por definição, extemporânea, constituindo-se assim como um tempo de vida que é sempre, também, um tempo de morte.

É com isso que o leitor terá de se ver na cena de leitura tanto do texto traduzido quanto da obra original ao levar essas questões todas em consideração, reconhecendo na chamada tradução - que em sua negatividade proverbial costuma

15 A propósito dessa escuta há também muito o que se discutir, como bem vem lembrando Marcelo Jacques de Moraes (UFRJ) nas diversas ocasiões em que tivemos a chance de debater o assunto. Trata-se aqui, especialmente, de destacar a importância daquilo que uma escuta pode catalisar de atenção e cuidado às singularidades do outro - nesse caso específico, da tradução como forma singular de vida - por contraste ao regime da indiferença, que se impõe amplamente quando o que impera, como pressuposto da relação com a tradução, é uma condição de infância. Para além disso, é certo que precisamos caracterizar melhor essa escuta, distinguindo uma forma de escuta daquele leitor que não tem relação com a língua estrangeira de uma forma de escuta daquele leitor que tem relação com a língua estrangeira em questão; assim como precisamos fazer distinção entre a escuta de um leitor chamado profissional, que poderá ler o texto traduzido à luz de suas relações com a obra original, com a fortuna crítica, com as tradições de leitura da obra, com outras traduções, etc. (posição privilegiada dos críticos e dos pesquisadores da tradução), e a escuta de um leitor não-profissional, talvez muito pouco interessado em projetar sua leitura no horizonte dessas relações específicas, quiçá nem mesmo muito atento ao fato de ter nas mãos um texto traduzido, mas sempre interessado em projetar sua leitura no horizonte das questões

Revista Letras, que lhe importam.

Curitiba, UFPR, n. 95 46-59, jan./jun. 2017. ISSN 2236-0999 (versão eletrônica) 
se apresentar mais como uma forma de morte - também um tempo de vida e, no chamado original - que em sua condição aurática costuma se apresentar mais como forma de vida -, também um tempo de morte.

Para lembrar aqui da leitura dos versos que epigrafam este trabalho, caberá a esse leitor aprender a lição de flor suscitada pelos versos de Paul Celan, fazendo a escrita florescer em seus diferentes tempos: não no sentido de restituir-lhe novamente uma vida dimensionada como um futuro passado - não é de uma restituição de origem que se trata na cena de leitura -, mas, sim, no sentido de se permitir, a um só tempo, viver a escrita como uma flor da morte e vivê-la à flor da morte.

Para tanto, precisamos aprender a olhar para a tradução com outros olhos, precisamos aprender a ouvi-la com outros ouvidos. Mas isso só será possível se nos mostrarmos dispostos a acolher também a tradução como flor singular, no seu florescer sem igual, como flor voluntariosa, que extrapola sua condição de infância, como flor de vez temporana, que não floresce num tempo dado, nem num tempo herdado, nem num tempo prometido, mas nos tempos que ela prova serem os seus. 
Cardozo, M. M.

Da Morte, da

Vida e dos

Tempos de

Morte e de Vida

da Tradução
Referências

BENJAMIN, Walter. A tarefa do tradutor, tradução de Susana K. Lages. In: Escritos sobre mito e linguagem (1915-1921), apresentação, organização e notas de Jeanne Marie Gagnebin, tradução de Susana K. Lages e Ernani Chaves. São Paulo: Duas Cidades, Editora 34, 2011, p.101-119.

BERMAN, Antoine. A prova do estrangeiro: cultura e tradução na Alemanha romântica. Herder, Goethe, Schlegel, Novalis, Humboldt, Schleiermacher, Hölderlin, tradução de Maria Emília Pereira Chanut. Bauru: Edusc, 2002.

BERMAN, Antoine. Pour une critique des traductions: John Donne. Paris : Gallimard, 1995.

CELAN, Paul. Die Gedichte aus dem Nachlass. In: Paul Celan: Die Gedichte. Kommentierte Gesamtausgabe, org. Barbara Wiedemann. Frankfurt: Suhrkamp, 2003, p.433-557.

CELAN, Paul. Mohn und Gedächtnis: Vorstufen - Textgenese - Endfassung. Edição Crítica de Tübingen, org. por Jürgen Wertheimer. Frankfurt: Suhrkamp, 2004.

KOSELLECK, Reinhart. Futuro passado: contribuição à semântica dos tempos históricos, tradução de Wilma Patrícia Maas, Carlos Almeida Pereira. Rio de Janeiro: Contraponto, Ed. PUC-Rio, 2006.

ROSENZWEIG, Franz. Die Schrift und Luther. In: STÖRIG, H.J. Das Problem des Übersetzens. Darmstadt: Wissenschaftliche Buchgesellschaft, 1969, p.199-203.

Submetido em: 03/11/2016

Aceito em: 22/12/2016

Revista Letras,

Curitiba, UFPR,

n. 95 46-59,

jan./jun. 2017.

ISSN 2236-0999

(versão eletrônica) 